\title{
FEM ANALYSIS OF TEMPERATURE DISTRIBUTION OF A FLAT PLATE MOLD WITH HOLLOWS, HEATED BY DIRECT RESISTANCE HEATING
}

\author{
KAZUTO TANAKA, SHUN AKAMATSU, JUN NAKATSUKA \& TSUTAO KATAYAMA \\ Department. of Biomedical Engineering, Doshisha University, Japan
}

\begin{abstract}
In the automobile industry, the lightening of a car body has become more important than ever to reduce the $\mathrm{CO}_{2}$ emissions. Carbon Fiber Reinforced Thermoplastics (CFRTP), which are superior in recyclability, specific strength and specific modulus, are expected to be candidates for replacing traditional metal materials. To increase the application of CFRTP, which are expensive now, a low-cost and high-speed molding method should be developed. A high-frequency direct resistance heating method, which heats only the mold surface rapidly by skin effect, has been developed and shows better energy consumption compared to an induction heating method. In this high-frequency direct resistance heating method, the uniformity of temperature distribution of the mold surface is one of the important issues to be solved. In our previous study, making a hollow in the curved mold can control heat flux and provides the uniform temperature distribution. In this study, to obtain uniform temperature distribution of the flat plate mold, the influence of the depth and number of hollows in the flat mold were analyzed by using FEM analysis. Uniform temperature distribution can be obtained by increasing the number of the hollows, which increase heat transfer paths between the hollows.
\end{abstract}

Keywords: CFRTP flat mold, FEM analysis, temperature distribution, skin effect, high-frequency direct resistance heating, hollow.

\section{INTRODUCTION}

In the automobile industry, the lightening of a car body has become more important than ever to reduce the $\mathrm{CO}_{2}$ emissions. Carbon Fiber Reinforced Thermoplastics (CFRTP) are expected to be candidates for replacing traditional metal materials as they have many superior mechanical properties such as high-specific strength and high-specific-modulus [1], [2]. Although CFRTP which are using thermoplastic resin for the matrix which is expected to reduce the manufacturing time, its cost is still too high to use for automobile parts [3] and high-speed molding process should be developed. In CFRTP molding system high-speed heating and cooling system for mold is one of the important issues to be developed. For the high-speed heating method of the mold, high frequency induction heating system has been developed [4], [5]. To improve the energy consumption of the heating, a high-frequency direct resistance heating method, which heats only the mold surface rapidly by skin effect, has been developed. By applying direct resistance heating to the flat mold for CFRTP molding, the uniformity of the temperature distribution of the flat mold surface is one of the important issues to be solved [6]. In our previous study, making a hollow in the curved mold can control heat flux and provides the uniform temperature distribution [7]. In this study, to obtain the uniform temperature distribution of the flat plate mold, the influence of the depth and the numbers of the hollow in the flat mold were analyzed by using FEM analysis. 


\section{FEM ANALYSIS}

\subsection{Governing equation}

COMSOL Multiphysics (COMSOL AB) was used for finite-element analysis. Electric and Induction Currents (AC/DC Module) and General Heat Transfer (Heat Transfer Module) modules were used. In consideration of Electromagnetic field analysis, they are expressed in the following equations (eqns (1)-(4)) [8].

$$
\begin{gathered}
\nabla \times \boldsymbol{H}-\frac{\partial \boldsymbol{D}}{\partial t}=\boldsymbol{j}, \\
\nabla \times \boldsymbol{E}=-\frac{\partial \boldsymbol{B}}{\partial t}, \\
\nabla \cdot \boldsymbol{B}=0, \\
\nabla \cdot \boldsymbol{D}=\rho,
\end{gathered}
$$

where:

- $\rho=$ charge.

- $H=$ magnetic field.

- $\quad D=$ electric flux density.

- $j=$ current density.

- $E=$ electric field.

- $\quad B=$ magnetic flux density.

The governing equation of heat transfer module is expressed in the following equation (Eqn. 5):

$$
\rho C_{p} \frac{\partial T}{\partial t}-\nabla \cdot(k \nabla T)=Q
$$

where:

- $\rho=$ density.

- $C p=$ specific heat.

- $T=$ temperature.

- $t=$ time.

- $\quad k=$ heat conduction coefficient.

- $Q=$ heat source.

Heat source is calculated from the current density distribution. The coupled analysis is performed based on these expressions.

\subsection{Analyzed model}

Fig. 1 shows the flat mold model for FEM analysis. The flat mold was made of SUS430, whose size was $240 \mathrm{~mm} \times 130 \mathrm{~mm} \times 50 \mathrm{~mm}$ and on the both end of the mold copper electrodes, whose size was $10 \mathrm{~mm} \times 130 \mathrm{~mm} \times 5 \mathrm{~mm}$, were attached. To consider the heat radiation to the air, a layer of air of $250 \mathrm{~mm} \times 500 \mathrm{~mm} \times 400 \mathrm{~mm}$, was set around the mold. The electrical properties of each material are shown in Table 1. Fig. 2 shows the flat mold model with hollow for FEM analysis. The size of a rectangular hollow was $260 \mathrm{~mm}$ $\times 100 \mathrm{~mm} \times 5 \mathrm{~mm}$. The upper face of the flat mold is defined as the press face. To clarify the influence of the depth of the hollow on the temperature distribution for the flat mold model 
with hollow, FEM models (Fig. 3) with hollow at different depths $\mathrm{t}=5 \mathrm{~mm}, 10 \mathrm{~mm}$ and $15 \mathrm{~mm}$ were used. To clarify the influence of number of hollows on the temperature distribution for the flat mold model with hollow, FEM models (Fig. 4) with different number of hollows, $n$ $=1,2$ and 6 , were used. The initial temperature is set to $20^{\circ} \mathrm{C}$ and heating time is set at 60 seconds. The output power is set to $10 \mathrm{~kW}$ for all FEM analysis.

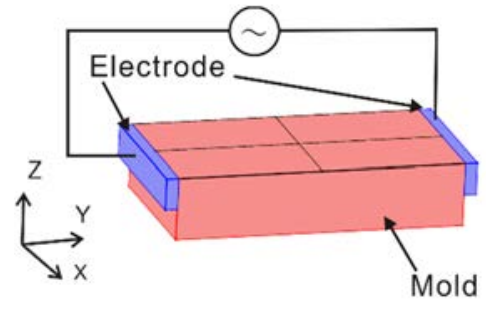

(i) Slant view

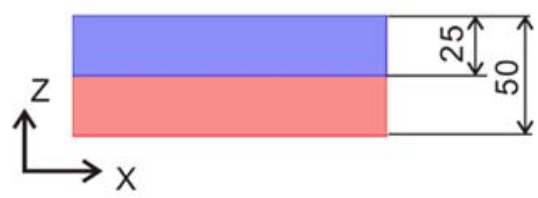

(ii) $\mathrm{X}-\mathrm{Z}$ cross section

Figure 1: FEM model for flat mold.

Table 1: Electrical properties of each material.

\begin{tabular}{|c|c|c|c|}
\hline & $\begin{array}{c}\text { Relative magne } \\
\text { tic } \\
\text { permeability }\end{array}$ & $\begin{array}{c}\text { Electric } \\
\text { conductivity } \\
{[\mathrm{S} / \mathrm{m}]}\end{array}$ & $\begin{array}{c}\text { Thermal } \\
\text { conductivity } \\
{[\mathrm{W} /(\mathrm{m} \cdot \mathrm{K})]}\end{array}$ \\
\hline Air & 1 & 0 & 0.257 \\
\hline Copper & 1 & $5.998 \times 10^{7}$ & 400 \\
\hline SUS430 & 122.4 & $1.666 \times 10^{6}$ & 25.6 \\
\hline
\end{tabular}

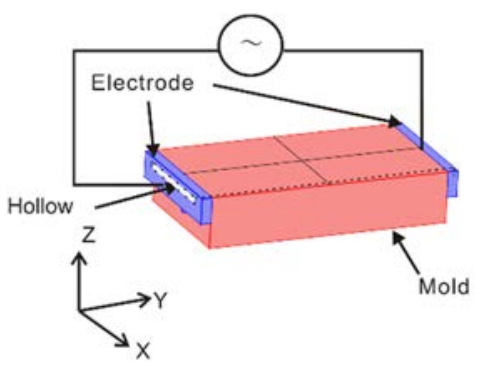

(i) Slant view

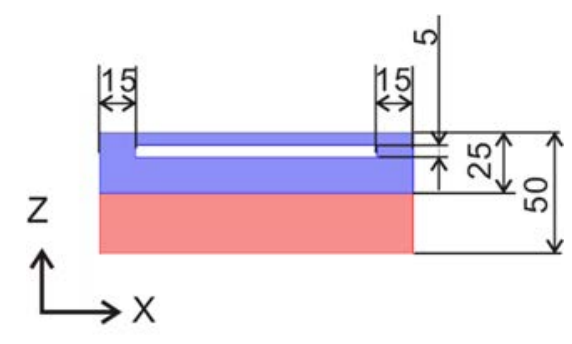

(ii) $\mathrm{X}-\mathrm{Z}$ section

Figure 2: FEM model for flat mold with hollow. 


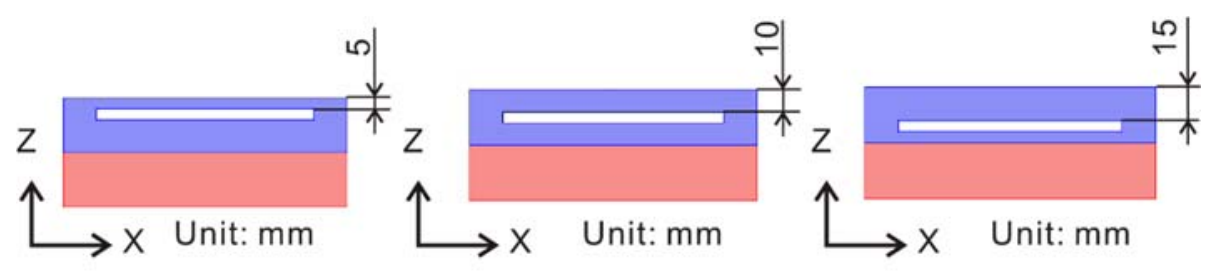
(a) $t=5$
(b) $t=10$
(c) $\mathrm{t}=15$

Figure 3: FEM model for flat mold with hollow at different depths.

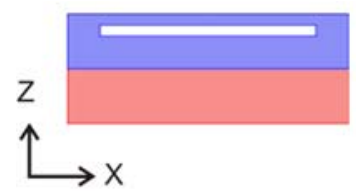

(a) $n=1$

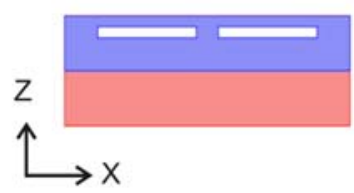

(b) $n=2$

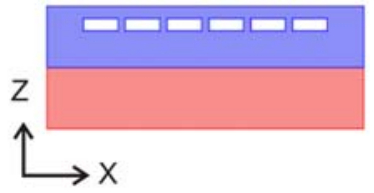

(c) $n=6$

Figure 4: FEM model for flat mold with different number of hollows.

\section{RESULTS AND DISCUSSION}

3.1 Influence of the depth of the hollow on the temperature distribution of the flat mold with hollow

Fig. 5 shows the temperature distribution of the press face without hollow and hollow for $\mathrm{t}=5 \mathrm{~mm}$. The temperature at the central part of the press face of the flat mold with hollow is higher than that of the mold without hollow. Fig. 6 shows temperature profiles of Line A on the surface of the mold without hollow and hollows for $t=5 \mathrm{~mm}, 10 \mathrm{~mm}$ and $15 \mathrm{~mm}$. The definition of Line A is illustrated in Fig. 6 as the surface line of the middle of the mold. The mold with hollow in shallower depth show higher temperature. Fig. 7 shows current density distribution for the Z-X cross section for the molds without hollow and hollow for $\mathrm{t}=5 \mathrm{~mm}$. By making hollow, the current density at the central part of the press face of the flat mold with hollow was concentrated in the surface of the mold. Fig. 8 shows heat flux of the Z-X cross section of the molds without hollow and hollow for $\mathrm{t}=5 \mathrm{~mm}$. For the mold without hollow, heat transferred uniformly from the heated surface part to the core of the mold. For the flat mold model with hollow, Point B shown in Fig. 8 has higher heat flux. As show in Fig. 6, this point shows lower temperature. This means that the heat flux plays an important role for the temperature distribution of the press face of the mold [6]. For the mold with hollow for $t=5 \mathrm{~mm}$, because of low thermal conductivity of the hollow (air), heat transfers to the surface of SUS430 instead of transfer from the heated surface part to the center of the mold. By hollowing out the mold, it is possible to raise the temperature at the central part of the press face of the flat mold.

3.2 Influence of the number of hollows on temperature distribution of the flat mold with hollow

Fig. 9 shows the temperature distribution of press face of the molds with hollow for $n=1,2$ and 6 . The increase of the number of hollow results in the uniform temperature distribution 
of the press face. Fig. 10 shows temperature profiles of Line A on the surface of the mold without hollow and hollows for $\mathrm{n}=1,2$ and 6 . The definition of Line A is illustrated in Fig. 10 as the surface line of the middle of the mold. Table 2 shows the maximum temperature, the minimum temperature, and temperature difference on Line A for each condition. The temperature difference for the mold with hollows for $n=6$ has the lowest temperature difference of $26^{\circ} \mathrm{C}$. Fig. 11 shows heat flux of the Z-X cross section of the molds when $\mathrm{n}=2$, and 6 . By increasing the number of the hollows, the heat transfer paths increases and uniform temperature distribution of the surface of the mold is obtained

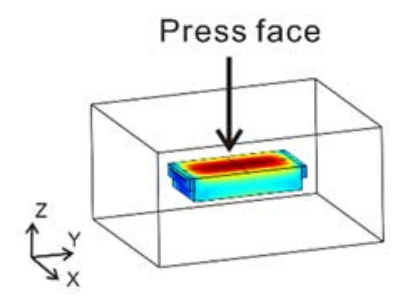

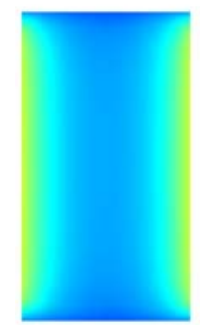

(a) Flat mold without hollow

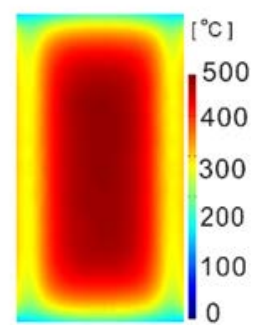

(b) Flat mold with hollow $(\mathrm{t}=5 \mathrm{~mm})$

Figure 5: Temperature distribution of press faces for flat molds without hollow and hollow for $\mathrm{t}=5 \mathrm{~mm}$.
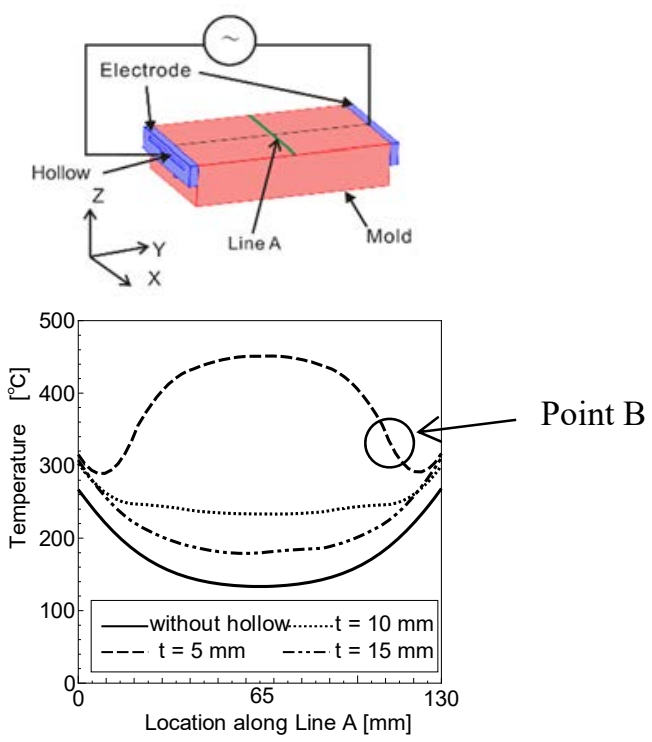

Figure 6: Temperature profiles of Line A on the surface of the molds without hollow and hollows for $\mathrm{t}=5 \mathrm{~mm}, 10 \mathrm{~mm}$ and $15 \mathrm{~mm}$. 


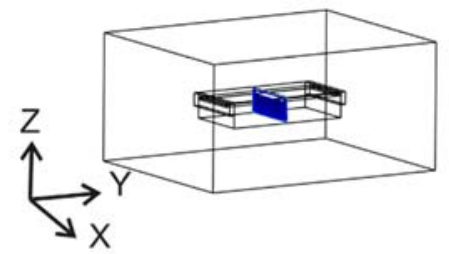

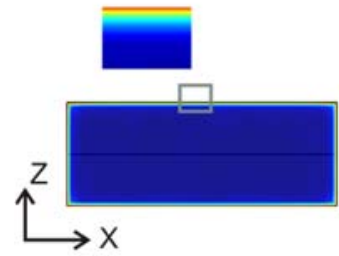

(a) Flat mold without hollow

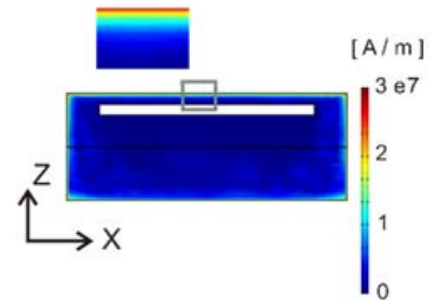

(b) Flat mold with hollow $(\mathrm{t}=5 \mathrm{~mm})$

Figure 7: Current density of the Z-X cross section of the molds without hollow and with hollow for $\mathrm{t}=5 \mathrm{~mm}$.

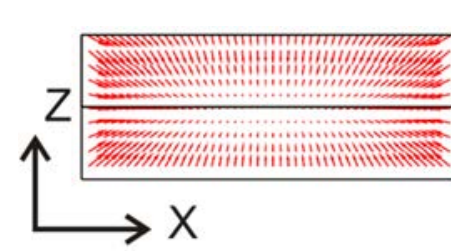

(a) Flat mold without hollow

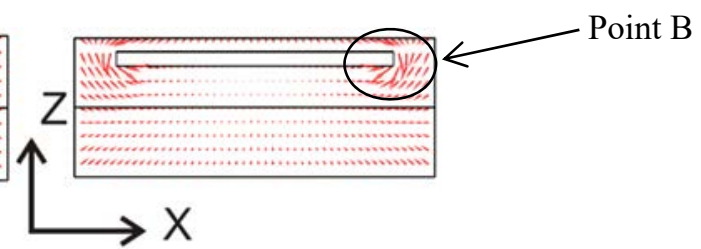

(b) Flat mold with hollow $(\mathrm{t}=5 \mathrm{~mm})$

Figure 8: Heat flux of the Z-X cross section of the molds without hollow and with hallow for $\mathrm{t}=5 \mathrm{~mm}$.

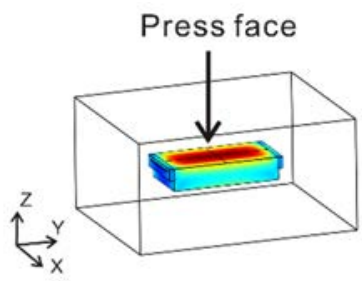

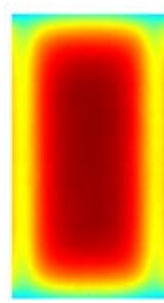

(a) $n=1$

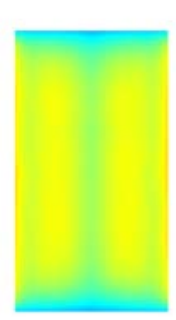

(b) $n=2$

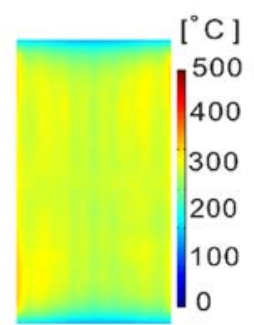

(c) $n=6$

Figure 9: Temperature distribution of press face of the molds with hollow for $n=1,2$ and 6 . 

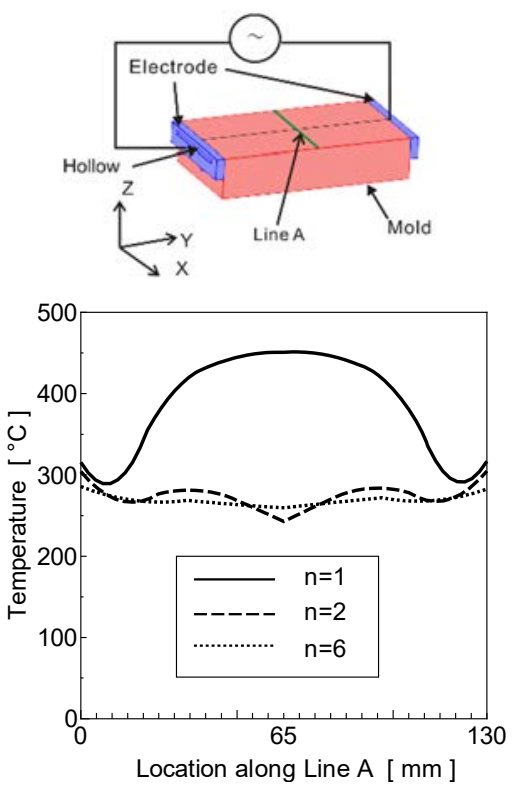

Figure 10: Temperature profiles of Line A on the surface of the molds without hollow and hollows for $\mathrm{n}=1,2$ and 6 .

Table 2: The maximum temperature, minimum temperature and temperature difference for profiles of Line A.

\begin{tabular}{|c|c|c|c|}
\hline $\begin{array}{c}\text { Number of } \\
\text { hollows }\end{array}$ & Maximum temperature $\left[{ }^{\circ} \mathrm{C}\right]$ & $\begin{array}{c}\text { Minimum temperature } \\
{\left[{ }^{\circ} \mathrm{C}\right]}\end{array}$ & $\begin{array}{c}\text { Temperature } \\
\text { difference }\left[{ }^{\circ} \mathrm{C}\right]\end{array}$ \\
\hline 1 & 724 & 564 & 159 \\
\hline 2 & 304 & 242 & 61 \\
\hline 6 & 285 & 259 & 26 \\
\hline
\end{tabular}

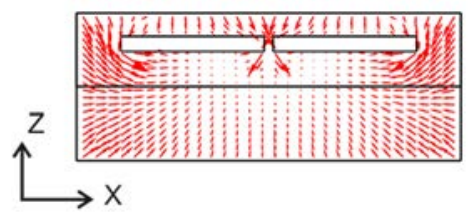

(a) Flat mold with hollow $(\mathrm{n}=2)$

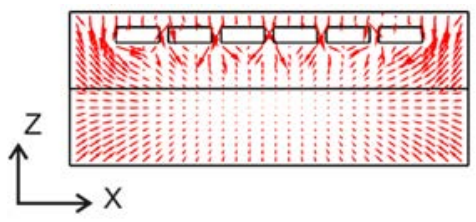

(b) Flat mold with hollow $(\mathrm{n}=6)$

Figure 11: Heat flux of the Z-X cross section of the molds with hallow for $n=2$ and 6 .

\section{CONCLUSIONS}

In this study, to reveal the temperature distribution of the flat mold with hollow and to obtain the uniform temperature distribution, the influence of the depth and number of hollows on the flat mold was analyzed by using FEM analysis. The investigation yielded the following conclusions: 
1. By shallowing the depth of the hollow, the temperature at the central part of the surface of the flat mold becomes higher.

2. Uniform temperature distribution can be obtained by increasing the number of the hollows, which increase heat transfer paths between the hollows.

\section{REFERENCES}

[1] Offringa, A.R., Thermoplastic composites rapid processing applications. Composites Part A: Applied Science and Manufacturing, 27(4), pp. 329-336, 1996.

[2] Silverman E.M. \& Forbes, W.C., Cost analysis of thermoplastic composites processing methods for spacecraft structures. SAMPE Journal, 26(6), pp. 9-15, 1990.

[3] Wadahara, E. \& Kitano, A., Automotive lightweight structural elements of carbon fiber reinforced plastics. The Society of Fiber Science and Technology, 64(9), pp. 295301, 2008.

[4] Guichard, A. \& Feigenblum, J., High-speed processing: using electromagnetic induction. JEC-Composites, pp. 94-96, 2004.

[5] Tanaka, K., Kohashi, N., Kinoshita, Y., Katayama, T. \& Uno, K., Compression molding of carbon fiber reinforced thermoplastic using non-woven stitched multi-axial cloth by means of induction heating system. Journal of the society of materials science, 58(7), pp. 642-648, 2009.

[6] Chan, S.C., Minh, P.S. \& Chan, J.A., Mold Temperature control using high-frequency proximity effect induced heating. International Communications in Heat and Mass Transfer, 39, pp. 216-223, 2012.

[7] Tanaka, K., Yamada, S., Matsuura, Y. \& Katayama, T., FEM Analysis of Temperature Distribution of CFRTP Curved Pipe Mold Heated by High-Frequency Direct Resistance Heating. Materials Characterisation, 7, pp. 233-242, 2015.

[8] Ueda, H. \& Ishiyama, A., Numerical electromagnetic analysis for applied superconductivity I -basics of numerical electromagnetic analysis. Cryogenics and Superconductivity Society of Japan, 47(11), pp. 623-632, 2012. 